\title{
Artificial insemination with spermatozoa in formaldehyde
}

\author{
H. M. Dott, R. M. Moor and C. Polge \\ A.R.C. Unit of Reproductive Physiology and Biochemistry, University of Cambridge, U.K.*
}

The ability of formaldehyde to preserve the integrity of the membranes of spermatozoa, as indicated by eosin staining (Dott \& Foster, 1975), prompted an investigation to discover what other properties of spermatozoa were preserved by low concentrations of formaldehyde in vitro. In a series of experiments on bull, ram and boar spermatozoa it has been shown that spermatozoa rendered immotile by formaldehyde recovered their motility when the formaldehyde was removed by washing up to $12 \mathrm{hr}$ afterwards (H. M. Dott \& G. C. Foster, unpublished). To find out if fertility was preserved ewes and sows were inseminated with spermatozoa rendered immotile with formaldehyde.

Sheep

Fresh ram semen was diluted 1:1 with phosphate-buffered saline containing $0.025 \% \mathrm{HCHO}$ ( $\mathrm{v} / \mathrm{v}, 40 \%$ solution) and allowed to equilibrate for $2 \mathrm{~min}$ before insemination; all spermatozoa were immotile within $60 \mathrm{sec}$ of formaldehyde treatment. The formaldehyde-treated semen $(0 \cdot 1 \mathrm{ml})$ was deposited in the caudal end of each uterine horn of five Welsh Mountain ewes which had been injected s.c. with PMSG (1000 i.u.) on Day 12 of the cycle. Laparotomy and insemination were carried out $6-12 \mathrm{hr}$ after the onset of oestrus.

Of the three ewes autopsied 5 days after insemination, one had not ovulated and fertilized ova were present in the other two. Examination of the eggs after fixation and staining showed that $6 / 13$ had undergone normal fertilization and cleavage. Ewes 4 and 5 each had two ovulations; two normal fetuses were recovered from the ewe autopsied on Day 36 and the other ewe gave birth to a single normal lamb.

Pigs

The sperm-rich fraction of semen from 2 boars was diluted 1:1 with $\mathrm{Ca}^{++}$-free Krebs-Ringer containing $0.025 \% \mathrm{HCHO}(\mathrm{v} / \mathrm{v}, 40 \%$ solution) and kept in the laboratory at room temperature for 1 or $2 \mathrm{hr}$ when a further dilution of $1: 4$ with $\mathrm{Ca}^{++}$-free Krebs-Ringer containing $10 \mathrm{~mm}$-glucose was made. The 1:8 diluted semen $(50 \mathrm{ml})$ was inseminated in the normal way on the 2 nd day of oestrus and the sows were slaughtered 3 days later. Of the 5 sows inseminated, two had no fertilized eggs and one had unfertilized eggs in one horn; the eggs from the other horn were fertilized, but there was some evidence of degeneration. All the eggs recovered from the other sows were fertilized and were indistinguishable from eggs fertilized with normal spermatozoa.

It thus seems possible to obtain normal fertilization from spermatozoa which have been pretreated with a low concentration of formaldehyde. This concentration is also capable of stabilizing the membranes of the spermatozoa and treatment of spermatozoa with formaldehyde before freezing may therefore be one way of preventing the changes which occur in boar (Wilmut \& Polge, 1974) and ram (Jones \& Martin, 1973) spermatozoa during freezing.

\section{References}

DOTT, H.M. \& FosteR, G.C. (1975) Preservation of differential staining of spermatozoa by formol citrate. J. Reprod. Fert. 45, 57-60.

JONES, R.C. \& MARTIN, I.C.A. (1973) The effects of dilution, egg yolk and cooling to $5^{\circ} \mathrm{C}$ on the ultra- structure of ram spermatozoa. J. Reprod. Fert. 35 , 311-320.

Wilmut, I. \& Polge, C. (1974) The fertilizing capacity of boar semen stored in the presence of glycerol at 20, 5 and $-79^{\circ}$ C. J. Reprod. Fert. 38, 105-113.

\footnotetext{
* Postal address: Animal Research Station, 307 Huntingdon Road, Cambridge, U.K.
} 